\title{
Ensino das lutas: dos princípios condicionais aos grupos situacionais ${ }^{1}$
}

\author{
Mariana Simões Pimentel Gomes* \\ Marcio Pereira Morato ${ }^{* *}$ \\ Edison Duarte*** \\ José Júlio Gavião de Almeida****
}

\begin{abstract}
Resumo: Este estudo buscou classificar e identificar princípios comuns no ensino das Lutas. Para tal, foram realizadas entrevistas semiestruturadas com professores e mestres em diferentes modalidades. Após a Análise de Conteúdo dos dados, percebemos que as Lutas dispõem de princípios condicionais (contato proposital, fusão ataque/defesa, oponente/alvo, imprevisibilidade e regras) determinantes para a compreensão e leitura de sua dinâmica interna. Desta forma, foi possível classificar as Lutas com base em denominadores comuns transferíveis (grupos situacionais), passíveis de serem ensinados antes da prática especializada, visando ao desenvolvimento global do aluno e não apenas à repetição descontextualizada de gestos técnicos.

Palavras-chave: Artes marciais: educação. Esportes.
\end{abstract}

\footnotetext{
${ }^{1}$ Este artigo é oriundo da dissertação de Mestrado da autora GOMES, Mariana Simões Pimentel. Procedimentos Pedagógicos para o Ensino das Lutas: Contextos e Possibilidades, defendida na Faculdade de Educação Física da Unicamp, 2008, e financiada pelo Conselho Nacional de Desenvolvimento Científico e Tecnológico (CNPq).

" Mestre em Atividade Física Adaptação e Saúde. Grupo de Estudos e Pesquisa em Atividade Motora Adaptada (GEPEAMA). Faculdade de Educação Física. Universidade Estadual de Campinas. Campinas, SP, Brasil. E-mail: marianaspg@gmail.com

"* Mestre em Atividade Física Adaptação e Saúde. Grupo de Estudos e Pesquisa em Atividade Motora Adaptada (GEPEAMA). Grupo de Estudo e Pesquisa Educação Física e Cultura (GEPEFIC). Faculdade de Educação Física. Universidade Estadual de Campinas. Campinas, SP, Brasil. Email: mpmorato@gmail.com

*** Professor Doutor da Universidade Estadual de Campinas. Grupo de Estudos e Pesquisa em Atividade Motora Adaptada (GEPEAMA). Faculdade de Educação Física. Universidade Estadual de Campinas. Campinas, SP, Brasil. E-mail: edison@fef.unicamp.br

**** Professor Doutor da Universidade Estadual de Campinas. Grupo de Estudos e Pesquisa em Atividade Motora Adaptada (GEPEAMA). Faculdade de Educação Física. Universidade Estadual de Campinas. Campinas, SP, Brasil E-mail: gaviao@fef.unicamp.br
} 


\section{INTRODUÇÃO}

Constantemente presente na bagagem cultural de diferentes civilizações no decorrer dos séculos, a $\operatorname{Luta}^{2}$ já foi reconhecida como rito, prática religiosa, preparação para a guerra, jogo, exercício físico, entre outros diversos significados que já lhe foram atribuídos, fosse ela ocidental ou oriental (BROUSSE, VILLAMÓN, MOLINA, 1999; ESPARTERO, 1999; VILLAMÓN, BROUSSE, 2002; VILLAMÓN, MOLINA, 1999).

Presentes nos diversos cenários da pedagogia do esporte, praticadas pelos seus diferentes personagens, as Lutas trazem para o mundo da educação física parcelas de tradição, religião, cultura, filosofia, rituais, disciplina, além de aspectos relacionados ao corpo, movimentos, passíveis de serem transmitidos, preservados e reorganizados às necessidades de cada contexto (BENTO, GARCIA, GRAÇA, 1999; PAES, 2002).

Por abrangerem uma gama infinita de movimentos, técnicas e características, tenta-se classificar as Lutas em função de uma série de critérios como: os objetivos de um combate, tipo de contato entre oponentes, suas ações motoras, distância entre oponentes, tipo de meta no enfrentamento. Esses agrupamentos unem as Lutas pelo que têm em comum, assim como as separam por suas diferenças. Segundo Espartero (1999), classificar os Esportes de Luta promove uma organização de elementos ou categorias de acordo com um determinado critério, que permite estabelecer uma diferenciação entre eles, o que facilitaria o ensino e a escolha do mais adequado a ser ensinado.

Nos Jogos Desportivos Coletivos (JDC), tal busca por princípios comuns foi iniciada por Bayer (1994) e Teodorescu (1984). Reconhecendo a presença de uma "lógica interna" para cada modalidade, regida pela intervenção das regras na solicitação de condutas parti-

\footnotetext{
${ }^{2}$ A escolha de um termo para tratar dessas atividades pode ser subjetiva dependendo do entendimento dos pesquisadores e de onde eles desejam chegar com o seu emprego. Arte Marcial, Esportes de Combate, Luta, Lutas. No contexto esportivo-educacional, no qual se fundamenta a escrita deste artigo, os termos Luta/Lutas contemplam as intenções e anseios do texto.
}

Movimento, Porto Alegre, v. 16, n. 02, p. 207-227, abril/junho de 2010. 
culares de jogadores e equipes, esses autores contribuíram muito para a Pedagogia do Esporte ao identificar características funcionais e estruturais comuns entre os JDC (BAYER, 1994). Tais esforços revolucionaram o ensino nessas disciplinas, ao permitirem pensar no ensino de uma base denominadora comum, transferível entre as diferentes modalidades e anterior à especialização em cada uma delas.

Motivado pela revolução no ensino dos JDC após as proposições dos autores supracitados e baseando-se na hipótese de proposição similar no âmbito das Lutas, este texto parte das classificações existentes sobre o fenômeno e também do conhecimento de mestres de diferentes modalidades para procurar compreender como as diferentes manifestações podem ser organizadas de acordo com os princípios comuns que as regem, com o intuito de contribuir para a estruturação pedagógica deste conhecimento na área da educação física.

\section{Materials e mÉtodos}

Com a delimitação do problema centrada no objetivo exposto anteriormente, as características dessa pesquisa requeriam uma investigação qualitativa de caráter descritivo e analítico. Desta forma, buscou-se absorver ao máximo as informações a serem colhidas em relatos orais dos sujeitos, discutindo e analisando seus conteúdos evidentes e latentes (THOMAS, NELSON, 2002).

Para tal, foi utilizada a entrevista semiestruturada (TRIVIÑOS, 1987) junto a quatro personagens ${ }^{3}$ do contexto das lutas, professores/ mestres das modalidades: Judô, Jiu Jitsu, Taekwondo, Karatê, Kendo e Esgrima. Todos os entrevistados possuem graduação e pós-graduação em Educação Física, além da formação marcial em mais de uma modalidade de luta. Acredita-se que tais pré-requisitos possibilitaram uma visão diferenciada acerca do tema em questão e, consequentemente, maior aprofundamento nas reflexões.

\footnotetext{
${ }^{3} \mathrm{O}$ projeto de pesquisa (com número de protocolo 108/2007) foi aprovado sem restrições pelo Comitê de Ética em Pesquisa da Faculdade de Ciências Médicas da Universidade Estadual de Campinas (CEP/FCM/UNICAMP).
}

Vovimento, Porto Alegre, v. 16, n. 02, p. 207-227, abril/junho de 2010. 
Para o tratamento, a análise e interpretação dos dados, recorreu-se a uma das técnicas da Análise de Conteúdo: a Análise de Enunciação. Esse tipo de análise é complementar à análise temática, que recorta o conjunto das entrevistas através de uma grelha de categorias projetada sobre os conteúdos (BARDIN, 1977).

As perguntas geraram um conjunto de temáticas - Características comuns das Lutas, Formas e Habilidades específicas -, fruto de aspectos latentes encontrados nos discursos dos interlocutores.

Após uma primeira análise de todos os discursos (entrevistas) para a determinação das temáticas supracitadas, realizou-se a inferência individual para que cada discurso fosse novamente analisado em sua singularidade, dentro dos diferentes indicadores (temas) e do sentido atribuído a eles por cada interlocutor.

Esta etapa proporcionou subsídios para a realização da inferência coletiva. Assim, pudemos discutir e refletir sobre os significados de cada temática.

\section{As LUTAS E SUAS CLASSIFICAÇÕES}

Para Espartero (1999), as Lutas podem ser categorizadas em "Esportes de Luta com agarre", "Esportes de Luta com golpes" e "Esportes de Luta com implemento".

$\mathrm{Na}$ primeira categoria, o agarre seria uma ação básica que representa os objetivos comuns entre as modalidades, tais como a derrubada (derribo), as projeções (proyecciones) e o controle no solo. Pode ser subdivida em decorrência da imposição inicial do agarre ou da não imposição desse agarre, como também pela finalidade "lutatória": finalizar o combate ao projetar o oponente ao solo ou continuar a luta no solo após a projeção. A categoria "Esportes de Luta com golpes" é subdividida de acordo com o tipo de golpe: apenas com os punhos; apenas com as pernas, ou mãos e pernas conjuntamente. A terceira categoria é a que trata dos "Esportes de Luta com implemento", na qual o objetivo é tocar o adversário com um implemento, como a espada, por exemplo (ESPARTERO, 1999). 
Essa classificação é feita considerando-se uma série de variantes, o que a torna confusa, já que, para entendê-la, deve-se pensar em vários critérios que, ao invés de agrupar as modalidades em "famílias", separam-nas em grupos e subgrupos a partir de suas diferenças. É uma divisão com base nas especificidades e não nos princípios comuns (GOMES, 2008).

Pensando num contexto esportivo que visa ao treinamento para competições, tal proposta apresenta uma riqueza de detalhes que tendem a influenciar diretamente no desenvolvimento das modalidades. Saber se existe a imposição do agarre pode determinar a tática/ técnica que um atleta vai utilizar, assim como o treino de uma modalidade que utiliza apenas punhos será diferente do de outra modalidade que permite o uso somente das pernas. Já num contexto educacional, em que dos objetivos do ensino das Lutas é proporcionar aos alunos a vivência e o conhecimento do fenômeno e suas manifestações, considerar tantos detalhes para classificar as Lutas tende a dificultar o processo, uma vez que as diferenças enfatizam as especificidades dos conteúdos (GOMES, 2008).

$\mathrm{Na}$ categoria do agarre, por exemplo, as possibilidades trazidas pelo autor podem mesclar-se numa única modalidade, e pertencer a um grupo não exclui a possibilidade de estar em outro. No caso dos "Esportes de Luta com golpes", as três subdivisões usadas pelo autor no contexto educacional não seriam de extrema relevância para o ensino, na medida em que todos os movimentos deste grupo são um conhecimento que deve ser explorado, independentemente das regras de uma modalidade (GOMES, 2008).

A classificação de Ramirez, Dopico e Iglesias (2000) assemelha-se à de Espartero (1999). No primeiro grupo, estão as modalidades nas quais existe o agarre ("Com agarre"), manifesto por meio das ações de derrubar e/ou excluir, controlar e fixar o adversário no espaço de luta. O segundo grupo não dispõe de movimentos que dependem do agarre, sendo denominado "Sem agarre". As ações motoras básicas deste grupo são golpear e impactar por meio de chutes e socos. O terceiro grupo possui o mesmo nome do segundo ("Sem agarre"), mas diferencia-se dele pela utilização de um implemento para tocar.

Wovimento, Porto Alegre, v. 16, n. 02, p. 207-227, abril/junho de 2010. 
Henares (2000) divide as ações motoras de um combate em “derrubar o adversário", "golpear" e "tocar". No primeiro grupo, ele também subdivide o que seria o agarre para Espartero (1999), adicionando ao desequilibrar/derrubar ações como fixar, excluir e controlar, também citadas por Ramirez, Dopico e Iglesias (2000).

Diferentemente dos outros autores apresentados, Henares (2000) expõe uma classificação de Jogos Desportivos de Luta que é uma compilação de classificações de autores espanhóis para modalidades de luta (GOMES, 2008). Embora em seu texto não haja explicação para o uso do termo jogos, através da leitura, percebese que o autor se refere aos jogos de luta como as formas não esportivizadas de Lutas, já os esportes de luta seriam as modalidades esportivizadas, reconhecidas por federações esportivas.

Desta forma, entende-se que sua classificação, diferentemente das anteriores, pode ser pensada para o conhecimento Luta/Lutas, independentemente das modalidades esportivizadas e suas regras específicas, e também para outras manifestações deste conhecimento, considerando aspectos comuns na dinâmica interna das Lutas e, consequentemente, valorizando métodos de ensino não centrados nas especificidades.

Nakamoto et. al. (2004), baseados em autores dos JDC (BAYER, 1994; GARGANTA, 1995; GRAÇA, 1995; TAVARES, 1995), consideram Luta uma categoria de jogo, regida pela lógica da oposição que possui como características específicas o ataque e a defesa de "alvos intrínsecos" (aos indivíduos) e a possibilidade de ataque simultâneo.

Eles definem quatro tipos de luta em função da relação dos lutadores com o "alvo" e com a "meta". O alvo é definido como o objeto a ser atingido e/ou defendido (indivíduos), enquanto a meta é o objetivo que se busca ao atingir o alvo. "Identificaram-se duas formas de relação com o alvo - tocando e segurando - e duas formas de relação com a meta - direta e indireta" (NAKAMOTO et. al., 2004).

Quando a meta é direta, a finalidade da luta pode ser segurar ou tocar o corpo do adversário (alvo) para pontuar ou terminar o combate. 
Se a meta é indireta, significa que as ações de tocar e segurar são um meio para finalizar o combate, seja através de uma projeção (objetivase atirar o adversário ao solo), de uma exclusão (segura-se o adversário para tirá-lo dos limites da área de combate) ou de um knock out ${ }^{4}$ (quando o adversário é golpeado até cair no chão)

\section{OS PRINCIPIOS CONDICIONAIS}

O modelo proposto por Bayer (1994) para os JDC foi aspecto motivador/norteador para que se pudesse buscar na análise dos dados a existência de denominadores comuns também para o fenômeno Luta. Tais denominadores são aqui chamados de Princípios Condicionais das Lutas:

- Contato Proposital

- Fusão Ataque/Defesa

- Imprevisibilidade

- Oponente(s)/Alvo(s)

- Regras

Independentemente da modalidade ou especificidade da luta, esses aspectos são condições indispensáveis para que uma atividade seja caracterizada como Luta, pois são capazes de delinear o conhecimento e diferenciá-lo dos demais.

Contato Proposital: pode ocorrer de várias maneiras (através das mãos, dos punhos, dos braços, das pernas, do corpo inteiro ou mediado por um implemento; contínua ou intermitentemente) e deve acontecer para que haja Luta e para que ela se desenvolva. Esse princípio condicional exige que os oponentes se toquem (intenção/ propósito) de alguma forma (técnica-tática) para conquistarem o objetivo da luta e obter êxito sobre os adversários.

Fusão Ataque/Defesa: assim como nos jogos coletivos e de oposição, tem de haver ataque e defesa em uma luta. O que difere

${ }^{4}$ Palavra em inglês utilizada para definir o fim de uma luta, como no boxe, por exemplo.

Wovimento, Porto Alegre, v. 16, n. 02, p. 207-227, abril/junho de 2010. 
as Lutas dessas outras atividades, nesse aspecto, é a possibilidade de tais ações serem simultâneas e até certo ponto fundidas, na medida em que é raro observá-las isoladamente, tanto na interação entre os indivíduos (em alguns momentos é difícil saber se os lutadores estão realizando ações ofensivas ou defensivas) ou nas ações de um dos lutadores (que pode defender com a perna e atacar com os membros superiores concomitantemente, por exemplo).

Já nos esportes coletivos, enquanto um time ataca, o outro obrigatoriamente está defendendo. Por mais que as equipes se organizem ofensivamente enquanto estão sem a posse da bola (defesa) ou defensivamente enquanto estão atacando, nunca as duas equipes finalizarão simultaneamente no alvo adversário, pois a finalização é dependente da posse de bola ou do implemento de jogo.

Imprevisibilidade: condição devido à relação de interdependência entre os lutadores e principalmente à possibilidade de as ações ofensivas e defensivas serem simultâneas. Não existem estratégias sequenciais completamente previsíveis numa luta, pois as ações de um lutador podem ou não ser respostas às ações do adversário, já que as estratégias de ação, anteriores à realização técnica, também podem ser simultâneas. Por mais que se treine ou se planeje uma forma de atuação numa luta, é a relação entre os oponentes que dita uma nova organização ou reestruturação do planejado a cada novo momento durante o combate. Essa imprevisibilidade faz com que o pensar a luta seja tão importante quanto o realizar a ação da luta.

Oponente/Alvo: isso implica dizer que o alvo, além de ser móvel, também pode executar ações de ataque e defesa. É essa condição que justifica o contato como uma exigência e que fundamenta a imprevisibilidade de um combate. Se os alvos são os próprios lutadores, o contato é o meio pelo qual deverão atingi-los, além de poder ser um fim à medida que determinadas técnicas dependem dele. Com o alvo personificado no adversário, a luta torna-se incondicionalmente imprevisível.

Regras: presentes em qualquer manifestação de Luta. Desde as mais primitivas, quando ainda não havia maneiras de registrá-las, 
elas já existiam: regras sociais, políticas ou éticas. As Lutas dependem das regras para sua legitimidade e elas devem ser respeitadas para que aconteça um combate. O que é permitido ou proibido tende a determinar as técnicas e táticas usadas pelos lutadores. É esse princípio condicional que define se, para atingir o alvo, devem-se usar as mãos, as pernas; se o contato deve ser direto; se haverá o uso do implemento etc.

Se a regra exige que os lutadores utilizem espadas para atingir uma determinada área do corpo do oponente, cabe a eles organizarem estratégias táticas (razões do fazer) aliadas às técnicas (como fazer) (GARGANTA, 1995) para a resolução dos problemas gerados. Portanto, são as regras que vão determinar as técnicas e táticas de uma modalidade (MORATO, 2007; TAVARES, 2002).

É por isso que o soco, por exemplo, pode ser executado de inúmeras maneiras, porque cada modalidade, a partir de suas regras específicas, desenvolveu técnicas historicamente para solucionar os problemas que surgiam em função dessas mesmas regras, ou seja, de que vale um soco com o objetivo de derrubar o adversário se a regra permite apenas que se encoste nele?

Assim, a partir dos princípios condicionais, podemos criar e legitimar inúmeras práticas como parte do conhecimento Luta, o que torna este universo ainda mais amplo e possível de ser ensinado, não somente por meio de suas especificidades, mas principalmente por todas as características que se têm em comum.

\section{DAS ESPECIFICIDADES AOS PRINCÍPIOS COMUNS}

O fenômeno Luta abrange uma série de modalidades institucionalizadas que passaram pelo processo de criação de técnicas baseadas nas regras de cada uma, isso foi aprendido pelos praticantes, tornou-se tradição e vem sendo transmitido nas mais diferentes culturas.

Cada modalidade carrega consigo sua história, sua origem, sua vestimenta, suas tradições e características que competem a cada manifestação de Luta. Mesmo com os princípios condicionais, existem fatores que diferenciam uma modalidade da outra e até uma 
única modalidade pode ter diferentes vertentes. Porém, a dinâmica interna e algumas técnicas tradicionais de cada uma, muitas vezes, podem ser comuns a outras modalidades.

Ao discutir as possíveis características comuns entre modalidades de luta, os entrevistados demonstraram uma convergência de ideias no que se refere ao contato entre oponentes (princípio condicional):

[...] acho que a maioria das lutas que tem contato físico direto, Judô... tanto o Judô quanto o JiuJitsu acho que um completa o outro [...] Jiu-Jitsu brasileiro ele se completa com o Judô porque o Judô também tem luta no solo [...] agora quanto às outras lutas, a luta Greco romana [...] a luta de contato, a Luta livre, o Sumô também é uma luta de contato como várias outras lutas [...] (E1).

[...] em algumas características, em algumas projeções que tenham o contato mesmo, por exemplo, do karatê para o judô tem algumas características bem comuns, bem próximas mesmo [...] (E2).

Os entrevistados citam uma série de modalidades nas quais o contato entre os oponentes pode variar, de acordo com o regulamento, mas é parte da lógica interna da luta. Algumas habilidades são recorrentes no repertório de diversas modalidades, podendo ser complementares umas às outras, como as projeções existentes no judô, jiu jitsu, luta livre, que dependem do agarre para sua execução. O soco utilizado no boxe, por exemplo, pode ser usado com objetivos e maneiras de execução diferentes no karate, taekwondo, kung fu etc. Com isso, o aprendizado de um soco específico de uma modalidade pode facilitar a realização de uma habilidade semelhante em outra luta, complementando o ensino.

Percebe-se uma aproximação das modalidades de contato direto em um mesmo grupo, o que também pode ocorrer com as modalidades que não têm contato direto, mas possuem outras características relacionadas a ele em comum, como o semicontato ou o contato mediado por um implemento. 
As características que permitem aproximações em grupos, citadas pelos entrevistados, em geral, são de caráter motor e, embora prevaleçam na iniciação, o ensino das Lutas agrega valores filosóficos, místicos, relacionados à tradição e à origem de cada modalidade. Isso é histórico e inerente a cada uma.

[...] a única modalidade que eu vi e tem muita semelhança assim é o Kendo, que é a Esgrima japonesa. Apesar de ela ter mais uma concepção tradicional, ela, a Esgrima do oriente ficou muito mais próxima da Filosofia, muito mais próximo inclusive do místico, do religioso [...] e a esgrima do Ocidente [...] caminhou para área atlética, mas a essência em si das posições, da técnica até da própria guarda elas são muito semelhantes e o treinamento começa muito parecido. (E3)

[...] em relação à Esgrima, é diferente da Esgrima Ocidental, é uma Esgrima típica, né, do Japão, dos samurais japoneses, mas usa todos os rituais, as vestimentas [...], é uma armadura que se põe sobre um kimono [...] o budismo, né, aspectos filosóficos e religiosos. (E4)

[...] Eu não posso dizer que as empunhaduras, as pegadas, as técnicas dessa modalidade como esporte elas não possam estar relacionadas, mas elas são limitadas, né? (E4)

Quando comparam a Esgrima (ocidental e oriental - Kendo), expõem diferenças em relação aos aspectos tradicionais, filosóficos e religiosos correspondentes à cultura oriental, definindo a Esgrima como esportivizada e o Kendo, mais tradicional, atrelado aos costumes originais. ${ }^{5}$ Em relação aos movimentos com os implementos, consideram a postura, algumas posições e técnicas comuns na iniciação. A presença de um implemento nas modalidades, qual seja, a espada, requer, no processo de ensino-aprendizagem, maneiras semelhantes de manipulação, formas de deslocamento, esquivas, ruptura dos padrões de luta de contato e semicontato e incorporação da espada na lógica da luta. Para atingir o adversário, é necessária a utilização do implemento e para isso os alunos devem ter a oportunidade de 
aprender as diversas maneiras (empunhaduras, pegadas, ambidestria de manipulação) de utilizá-lo.

Percebe-se que as características comuns entre as modalidades citadas se relacionam a aspectos culturais, ao contato ou à distância entre oponentes num enfrentamento e, sobretudo a algumas habilidades teoricamente específicas das modalidades. Capacidades físicas como força, flexibilidade, equilíbrio e coordenação aparecem como necessárias para o desenvolvimento das habilidades específicas.

A distância pode ser entendida de duas formas. A primeira refere-se a uma única modalidade, na qual podem existir estratégias que variam de acordo com o espaço entre os oponentes (curto, médio ou longo). Desta maneira, usa-se a distância como um meio para diversificar o treinamento e as movimentações do karatê.

[...] a gente pode trabalhar a distância curta, quando a gente deixa os dois bem próximos mesmo, então, por exemplo, eu colocar um pé junto do outro [...] A distância média dá para trabalhar, por exemplo, com a faixa, amarrar a faixa em um e amarrar a faixa no outro e a faixa ficar estendida, então a gente deixar essa faixa estendida ele vai saber quando é distância média [...] distância longa é quando está a mais do que isso, por exemplo, um cara que tem que trabalhar muito golpe de braço, ele sabe que ele vai ter que ter uma impulsão do membro inferior para chegar a esse golpe numa distância longa. (E2)

O entrevistado entende a distância como um componente estratégico que está dividido em três categorias - curta, média e longa , que depende da imprevisibilidade da luta e do jogo do adversário. Acreditando que, na mesma modalidade, é possível pensar a distância de três maneiras, como se cada técnica exigisse um espaço distinto para ser executada.

A outra forma de se entender distância é pensar num requisito

\footnotetext{
${ }^{5} \mathrm{~A}$ esgrima oriental, à qual se refere o entrevistado, corresponde ao kendo. Segundo Draeger e Smith (1969), existe uma matriz oriental comum entre as modalidades que derivaram do Budo (conjunto de normas éticas, morais, sociais, aliado aos aspectos filosóficos, religiosos imbricados na natureza e no próprio indivíduo) que não se aplica às modalidades oriundas do ocidente.
}

Movimento, Porto Alegre, v. 16, n. 02, p. 207-227, abril/junho de 2010. 
para que aconteça um combate. O contato é um princípio condicional e vai depender da distância entre os adversários para ser definido.

Uma modalidade de curta distância possui um espaço praticamente nulo entre os oponentes e, para a realização das técnicas e alcance dos objetivos da luta, é necessário que os praticantes se coloquem em contato direto (contato como um meio para o fim).

A distância média seria um espaço moderado que permite a aproximação em situações de ataque entre os oponentes, pois a intenção e o propósito ofensivo vão determinar a distância entre os lutadores. Os golpes caracterizam o contato e não dependem dele para acontecer como na curta distância (o contato é um fim e não o meio).

Já na longa distância, definida pela presença de um implemento, deve haver uma distância maior entre os oponentes para que os mesmos possam manipular de forma adequada esse implemento, fazendo com que o contato entre eles seja através de uma espada, por exemplo (contato também é um fim).

Mas o instrumento faz com que você fique distante, a área é questão de território, no judô, por exemplo, que tem que ter a proximidade [...] você pode girar, você tem que tirá-lo, né, afastá-lo, jogar pra fora [...] agora, no kendo não, você tem que realmente ir pra destruir quem está no território [...] você tem que estar distante e $[. .$.$] a relação que tem de proximidade com ele é a$ ponta da shinai [espada utilizada no kendo]. (E4)

A presença do implemento determina a denominação do Kendo como luta de longa distância. Um lutador tem que se manter afastado para estar protegido. A proximidade também vem em função da ação do ataque e se relaciona com o implemento, como se este fosse uma extensão do corpo de quem luta.

O entrevistado estabelece diferenças entre modalidades de luta através da distância entre os oponentes. Coloca o Judô como luta na qual existe proximidade entre os adversários, podendo ocorrer ameaças de ataque, que refletem uma disputa de território de combate. Segundo o entrevistado, algo similar ocorre no Taekwondo, modalidade de média distância, na qual acontecem aproximações e ações de ata- 
que que podem estar disfarçadas, para iludir o adversário. No Kendo, pela necessidade de distância entre os oponentes (proteção e presença do implemento), um ataque não acontece com o objetivo de disputar o território de luta como nas outras modalidades, mas sim com o objetivo de se pontuar rapidamente para terminar o combate.

No Kendo, pela necessidade de distância entre os oponentes (proteção e presençado implemento), um ataque não acontece com o objetivo de disputar o território de luta como nas outras modalidades, mas sim com o objetivo de se pontuar rapidamente para terminar o combate: [...] no Judô não tem jeito, você tem que segurar para poder tentar derrubar o adversário. (E1)

Como situações específicas da curta distância estão verbos como segurar, pegar, projetar, rolar, cair, desequilibrar, que demonstram a necessidade do contato direto entre os oponentes na prática dessas modalidades. ${ }^{6} \mathrm{Na}$ média distância estão presentes os chutes, socos e as sequências combinadas; na longa distância, as empunhaduras, habilidades manipulativas e posturas.

A classificação a seguir (Figura 1) organiza as situações de Luta de acordo com a distância existente entre os oponentes. A ênfase em determinado Grupo Situacional é definida por um dos princípios condicionas: as regras. Elas delimitam como deve ser o contato na luta, determinando a distância entre as pessoas que vão lutar e, consequentemente, as situações mais corriqueiras em cada grupo.

Nesse sentido, partindo das peculiaridades de várias modalidades, relatadas pelos entrevistados e interpretadas pelos autores mediante o referencial teórico utilizado, pode-se chegar a uma definição de Luta que abrange suas manifestações e pontos comuns, que, quando unidos às abordagens, definições e classificações estudadas neste artigo, permitem uma conceituação deste fenômeno.

\footnotetext{
${ }^{6}$ Nas modalidades de contato direto ou curta distância, há uma diferenciação baseada na imposição ou não do contato inicial. Neste caso, as habilidades e estratégias relacionadas ao início do combate vão diferir de uma modalidade para outra. Entretanto, todas as modalidades estão sujeitas às consequências da esportivização, tal como o Judô, que foi criado em objetivos exclusivamente educacionais e no qual o contato direto era imposto inicialmente, além de uma condição para o começo da luta. Atualmente, esse contato leva muitos minutos da luta, sendo disputado, modificando não somente a razão original pela qual foi criado o Judô, mas também a leitura da luta.
} 


\begin{tabular}{|c|c|c|c|}
\hline \multirow[b]{2}{*}{ 告 } & $\begin{array}{c}\text { CURTA } \\
\text { DISTÂNCLA }\end{array}$ & $\begin{array}{c}\text { MÉDLA } \\
\text { DISTÂNCLA }\end{array}$ & $\begin{array}{c}\text { LONGA } \\
\text { DISTÂNCLA }\end{array}$ \\
\hline & $\begin{array}{l}\text { - Desequilibrar } \\
\text { - Rolar } \\
\text { - Projetar } \\
\text { - Cair } \\
\text { - Controlar } \\
\text { - Excluir }\end{array}$ & $\begin{array}{l}\text { - Tocar } \\
\text { - Golpear } \\
\text { ○ Mãos, braços, } \\
\text { cotovelos } \\
\text { ○ Pernas, joelhos, } \\
\text { pés }\end{array}$ & $\begin{array}{l}\text { - Tocar } \\
\text { (intermédio de } \\
\text { um implemento) } \\
\text { - Manipular } \\
\text { (implemento) }\end{array}$ \\
\hline
\end{tabular}

Fig. 1 - Grupos Situacionais de Luta.

Essas ações são recorrentes também na fala dos entrevistados e representam a aproximação de elementos comuns em modalidades de luta já existentes.

LUTA: Prática corporal imprevisível, caracterizada por determinado estado de contato, que possibilita a duas ou mais pessoas se enfrentarem numa constante troca de ações ofensivas e/ou defensivas, regida por regras, com o objetivo mútuo sobre um alvo móvel personificado no oponente.

Acredita-se que essa definição contempla os princípios condicionais das Lutas, bem como a dinâmica interna de qualquer manifestação do fenômeno.

Entretanto, existe um ramo das Lutas, também abordado pelos entrevistados, com nomenclaturas distintas, que seguramente é uma expressão do conhecimento Luta: as Formas (katas, katis).

São elementos presentes nas manifestações de Luta, porém, não entram nessas classificações e definições apresentadas pois acredita-se que não possuem os mesmos objetivos e lógica interna inerentes às Lutas, já que podem ser ensaiados como uma coreografia. Porém, há necessidade de se reforçar, inclusive, que as Formas também se caracterizam como uma maneira de manifestação esportiva, através de competições de alto rendimento ou de ensaios esportivos no processo de ensino-aprendizagem para o aperfeiçoamento de lutas entre oponentes.

Nos casos de aprendizagem, treinamentos ou competições de Formas sem a necessidade de interferência direta do oponente, estas são compreendidas como um estado de oposição simulada, pois 
não compartilham da imprevisibilidade presente nas outras manifestações de combate. Utilizam-se das técnicas tradicionais das modalidades, da sua maneira de execução, dos princípios de ataque e defesa, porém, não dependem exclusivamente de um parceiro ou adversário para serem desenvolvidas, apesar de se buscar em suas ações, como objetivo secundário, a aplicação de golpes em um adversário imaginário.

[...] No Judô existem os katas [...] O estudo das formas, formas tradicionais, tem técnicas [...] que eram utilizadas pelos guerreiros, samurais [...] inclusive são técnicas que não são utilizadas nas competições, porque os guerreiros utilizavam armaduras, [...] então é bem diferente do Judô competitivo, uma tradição de demonstração de onde vieram todas as técnicas $[\ldots](\mathrm{E} 1)$.

Se a gente pegar lá os estágios da mobilidade [...] o processo de repetição é o que predomina ali, o primeiro kata do karatê que éo [...] tem 21 movimentos $[\ldots](\mathrm{E} 2)$

As Formas dependem da peculiaridade de cada modalidade, porém definem-se em movimentos técnicos de ataque e defesa, ensinados de maneira fragmentada, que podem ser executados individualmente (os adversários seriam imaginários) ou na presença de outros companheiros (em grupo ou duplas, como no Judô). Algumas modalidades não possuem Formas como um conteúdo tradicional, mas dispõem de movimentos específicos, treinados isoladamente, que serão empregados num combate.

A finalidade das Formas também relaciona-se à conservação da tradição e cultura da modalidade, como um meio dos praticantes conhecerem as técnicas mais antigas, já não utilizadas com a modernidade.

Com base nas falas dos entrevistados, o termo pode ser definido da seguinte maneira:

FORMAS: Combinação de elementos e técnicas tradicionais, que expressam a essência dos movimentos das Lutas, arranjados numa sequência pré-estabelecida, podendo ser executada na presença de adversários reais ou imaginários. 
Deste modo, entendendo as Lutas e toda sua complexidade e dialogando com os entrevistados, foi possível pensar numa proposta de organização deste conhecimento com uma finalidade que anseia transcender as categorizações. Muito mais do que ordenar o conhecimento, ou dividi-lo em classes, deseja-se contribuir para os atuais e futuros processos de ensino-aprendizagem das Lutas no que diz respeito a sua disseminação para diferentes contextos e personagens da Pedagogia do Esporte (Fig. 2).

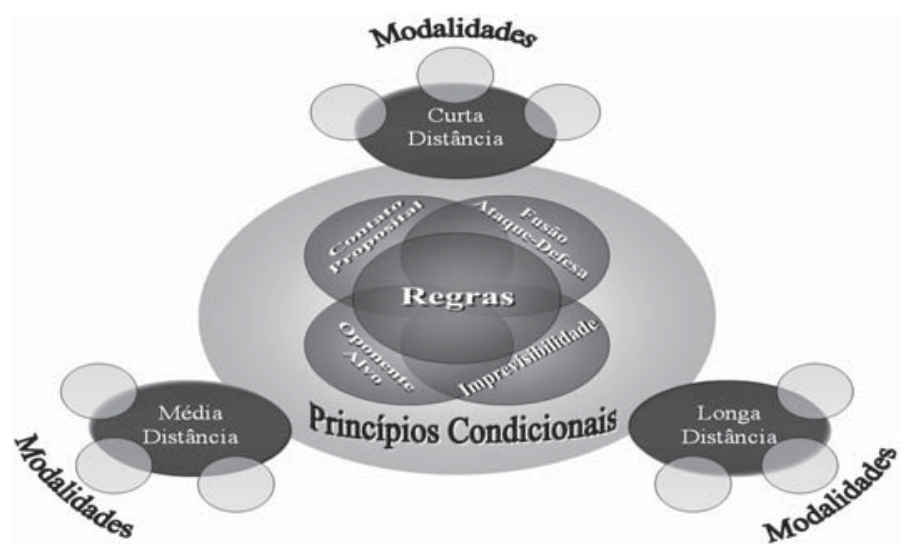

Figura 2 - Sistema de interações das Lutas

O sistema representa a complexidade de interações entre os elementos do Fenômeno Lutas e suas manifestações. Desta forma, é possível transcender a linearidade das classificações apresentadas, pensando num ensino global que enfatize os princípios condicionais das Lutas e os aspectos comuns entre as modalidades na iniciação, organizados pela distância entre oponentes (curta, média e longa), antes de ensinar as especificidades das modalidades tradicionais de luta.

\section{CONSIDERAÇÕES FINAIS}

Os princípios condicionais (contato proposital, fusão ataque/ defesa, imprevisibilidade, oponente/alvo e regras) regem as Lutas e as caracterizam. Buscar descobri-los, analisar e refletir sobre eles possibilitou criar uma definição para as Lutas e também para as Formas, uma de suas manifestações.

A análise das classificações de "esportes de luta" existentes (revisão de literatura) e da fala dos entrevistados possibilitou classificar as Lutas em função da distância entre os oponentes, apontando as ações comuns nos grupos situacionais, de acordo com as proximidades 
entre as situações tático/técnicas, determinadas pela lógica de cada modalidade de luta com suas especificidades regulamentares.

Essa classificação permitiu transcender as divisões apresentadas para as ações de Luta, figurando na elaboração de um sistema de interações entre as manifestações do fenômeno, que demonstrou a complexidade do conhecimento. Um sistema que se apresenta como base denominadora comum, transferível entre as diferentes modalidades, anterior à prática especializada, pois mais do que a simples e descontextualizada repetição de gestos técnicos, visa ao desenvolvimento global do aluno, com ênfase no processo cognitivo de leitura da luta e a consequente elaboração de estratégias táticas para a resolução de problemas de diferentes ordens surgidos em sua dinâmica. 
Martial Arts teaching: From the conditional principles to the situational groups

Abstract: This study aimed to classify and identify common principles in the Martial Arts teaching. For that, we used semi-structured interviews, with teachers and masters in different modalities. After the Contend Analysis of the data, we realized that the Martial Arts have conditional principles (intentional contact, attack/ defense fusion, opponent/target, unpredictability and rules) determinant for the understanding and reading of any combat's internal dynamic. So we could classify the Martial Arts based on common and transferable denominators (situational groups) which can be taught before the specialized practice, looking forward to the students global development, not only the isolated repetition of the technical moves.

Keywords: Martial arts: education. Sports.

La Enseñanza de las Luchas: de los principios
condicionales a los grupos situacionales
Resumen: Este trabajo buscó clasificar y identificar
principios comunes en la enseñanza de la Lucha. Para
eso realizamos entrevistas semi-estructuradas con
profesores y maestros en diferentes modalidades.
Después de la Análisis de Contenido de los datos,
percibimos que las Luchas tienen principios condicionales
(contacto proposital, fusión ataque/defensa, oponente/
meta, imprevisibilidad y reglas) determinantes para la
comprensión y lectura de su dinámica interna. Así,
pudimos clasificar las Luchas con base en denominado-
res comunes y transferibles (grupos situacionales),
que pueden ser enseñados antes de la práctica es-
pecializada, buscando el desarrollo global de los
alumnos sino solamente la repetición desentornada
de los gestos técnicos
Palabras clave: Artes marciales: educación. Deportes.

\section{REFERÊNCIAS}

BARDIN, L. Análise de conteúdo. Lisboa: Edições 70, 1977.

BAYER, C. O ensino dos desportos coletivos. Lisboa: Dinalivro, 1994.

BENTO, J.; GARCIA, R.; GRAÇA, A. Contextos da pedagogia do desporto: perspectivas e problemáticas. Lisboa: Livros Horizonte, 1999.

Wovimento, Porto Alegre, v. 16, n. 02, p. 207-227, abril/junho de 2010. 
BROUSSE, M.; VILLAMÓN, M.; MOLINA, J. P. El judo en el contexto escolar. In: VILLAMÓN, M. (Org.). Introducción al judo. Barcelona: Hispano Europea, 1999.

DRAEGER, D., SMITH, R. Asian Fighting Arts. Tokyo: Kodansha International, 1969.

ESPARTERO, J. Aproximación histórico-conceptual a los deportes de lucha In: VILLAMÓN, M. (Org.). Introducción al judo. Barcelona: Hispano Europea, 1999.

GARGANTA, J. Para uma teoria dos jogos desportivos coletivos. In: GRAÇA, A.; OLIVEIRA J. (Ed.). O ensino dos jogos desportivos. 2ed. Porto: Centro de Estudos dos Jogos Desportivos, Faculdade de Desporto da Universidade do Porto, 1995.

GOMES, M. S. P. Procedimentos pedagógicos para o ensino das lutas: contextos e possibilidades. 2008. 119f. Dissertação (Mestrado em Educação Física) - Faculdade de Educação Física Universidade Estadual de Campinas, Campinas, 2008.

GRAÇA, A. Os comos e os quandos no ensino dos jogos. In: GRAÇA, A.; OLIVEIRA J. (Eds.). $O$ ensino dos jogos desportivos. $2^{\circ}$ ed. Porto: Centro de Estudos dos Jogos Desportivos, Faculdade de Desporto da Universidade do Porto, 1995.

HENARES, D. A. Deportes de lucha. Barcelona: Inde, 2000.

MORATO, M. P. Futebol para cegos (futebol de cinco) no Brasil: leitura do jogo e estratégias tático-técnicas. 2007. 202f. Dissertação (Mestrado em Educação Física) - Faculdade de Educação Física, Universidade Estadual de Campinas, Campinas, 2007.

NAKAMOTO, H. O.; PUCINELI, F. A.; BOSCOLLO, F.; TRIANA, R. O; CASTRO JUNIOR, J. L.; SALGADO, J. V. V.; GOMES, M. S. P.; DAOLIO, J. Ensino de lutas: Fundamentos para uma proposta sistematizada a partir dos estudos de Claude Bayer. In: CONGRESSO CIENTÍFICO LATINO-AMERICANO DE EDUCAÇÃO FÍSICA 3. Piracicaba: UNIMEP, 2004. Anais... Piracicaba: UNIMEP, p. 1250, 2004.

PAES, R. R. A pedagogia do esporte e os jogos coletivos. In: ROSE Jr, D. (Org.). Esporte e atividade física na infância e na adolescência: uma abordagem multidisciplinar. Porto Alegre: Artmed, 2002.

RAMIREZ, F. A.; DOPICO, J. A.; IGLESIAS, E. Requerimientos motrices de la lucha leonesa. Consideraciones generales sobre el proceso de enseñanza-aprendizaje. In: RODRIGUEZ, C. (Org.). El entrenamiento en los deportes de lucha. Leon: L.Federación Territorial de Lucha, 2000.

TAVARES, F. O processamento da informação nos jogos desportivos. In: GRAÇA, A.; OLIVEIRA J. (Eds.). O ensino dos jogos desportivos. 2.ed. Porto: Centro de Estudos dos Jogos Desportivos, Faculdade de Desporto da Universidade do Porto, 1995.

TAVARES, F. Análise da estrutura e dinâmica do jogo nos jogos desportivos. In: BARBANTI, V. J.; AMADIO, A. C.; BENTO, J. O.; MARQUES, A. T. (Org.). Esporte e atividade física: interação entre rendimento e saúde. São Paulo: Manole, 2002. 
Ensino das lutas: dos princípios condicionados aos grupos situacionais.

TEODORESCU, L. Problemas de teoria e metodologia nos jogos desportivos. Lisboa: Horizonte, 1984.

THOMAS, J. R.; NELSON, J. K. Métodos de pesquisa em atividade física. Porto Alegre: Artmed, 2002.

TRIVIÑOS, A. N. S. Introdução à pesquisa em ciências sociais: a pesquisa qualitativa em educação. São Paulo: Atlas, 1987.

VILLAMÓN, M.; BROUSSE, M. El judo como contenido de la educación física escolar. In: CASTARLENAS, J.; MOLINA, P. (Orgs.). EI judo en la educación física escolar: unidades didácticas. Barcelona: Hispano Europea, 2002.

VILLAMÓN M.; MOLINA, J.P. La iniciación deportiva en Judo. In: VILLAMÓN, M. (Org.). Introducción al judo. Barcelona: Hispano Europea, 1999.

Recebido em: 12.08.2009

Aprovado em:11.02.2010

Pesquisa financiada pelo CNPq 